\title{
Función intercultural de la historieta en la enseñanza de la física y matemática universitaria
}

DOI: $10.46932 /$ sfjdv2n1-029

Received in: November 1st, 2020

Accepted in: December 30th, 2020

\section{Ronald Estela Urbina}

Docente Asociado de la Universidad Nacional Intercultural "Fabiola Salazar Leguía" de Bagua, Licenciado en Física. Bagua, Perú.

\section{Elisa Contreras Barsallo}

Docente de la I.E Túpac Amaru de Chiriaco-Imaza-Amazonas, Licenciada en Lengua y Literatura. Bagua, Perú.

\section{Carlos Rios-Campos}

Docente Investigador RENACYT. Universidad Nacional Toribio Rodríguez de Mendoza de Amazonas. Doctor en Gestión Universitaria. Bagua, Perú.

E-mail: carlos.rios@untrm.edu.pe

\section{Henrry Agreda Cerna}

Docente Asociado. Maestro en Administración de la Educación. Universidad Nacional José María Arguedas. Andahuaylas, Perú.

\section{Nemesio Santamaría Baldera}

Docente Auxiliar. Maestro en Administración Educativa y Desarrollo Sostenible. Licenciado en Física. Universidad Nacional Intercultural Fabiola Salazar Leguía de Bagua. Bagua, Perú.

\section{Pilar Ríos Campos}

Docente Principal. Maestra en Ciencias con Mención en Informática y Sistemas. Ingeniera de Sistemas. Universidad Nacional Pedro Ruiz Gallo. Chiclayo, Perú.

\section{Abel Salcedo Herrera \\ Licenciado en Administración. Articulador comercial - Avanza Rural. Chota, Perú.}

\section{David Salcedo Herrera}

Ingeniero en Industrias Alimentarias y Magister en Agronegocios por la Universidad de Buenos AiresArgentina. INNOVATE Perú- Especialista en Cultura y Gestión de la Innovación. Chota, Perú.

\section{RESUMEN}

El presente artículo muestra la investigación realizada en la Universidad Nacional Intercultural "Fabiola Salazar Leguía de Bagua" - UNIFSLB, con estudiantes de ingeniería civil del tercer ciclo de su formación profesional. Esta investigación resulta pertinente ya que nuestra población estudiantil en la universidad está conformada por mestizos y originarios de comunidades amazónicas de Perú. Este trabajo tiene como objetivo identificar en la historieta su función intercultural como una forma de expresión de los estudiantes originarios y mestizos respecto a la comprensión de un fenómeno físico o principio matemático ligado al conocimiento común. La historieta como herramienta usada en la labor pedagógica universitaria evidencia un recurso muy importante para exteriorizar el pensamiento del estudiante, que con lenguaje cotidiano y ligado a sus costumbres pretende comprender el conocimiento científico. 
Asimismo, se convierte en una oportunidad de revalorar sus saberes ancestrales a través del relato de situaciones o episodios de su entorno que fueron rescatados a través de sus antepasados o vivencias personales y se reflejan en sus producciones artísticas. El trabajo metodológico se realizó en tres momentos a lo largo del ciclo 2020-I que consistió en el diagnóstico de sus saberes respecto a historietas, paso seguido la elaboración y presentación virtual de la historieta y finalmente la socialización por medio de una videoconferencia, que permitió interactuar y conocer algo más de la cultura mestiza y awajúnwampis en un ambiente de tolerancia.

Palabras clave: Enseñanza, identidad cultural, física, matemáticas, pluralismo cultural.

\section{INTRODUCCIÓN}

La educación y la discriminación son fenómenos socioculturales que afectan las condiciones de vida de las personas y determinan, de manera decisiva, la necesaria inclusión de todos los sectores y grupos en el desarrollo de la sociedad (González, 2019).

A nivel latinoamericano se presentan numerosas iniciativas para promover las universidades interculturales, pero que demandan una mayor inversión en investigación y trabajo conjunto y organizado, para crear un modelo viable, competitivo y actual a las demandas sociales y desafíos actuales (Ríos, 2020).

La Universidad Nacional Intercultural "Fabiola Salazar Leguía” de Bagua - UNIFSLB es una de las cuatro universidades interculturales del Perú.

La revista científica de la Universidad Nacional Intercultural Fabiola Salazar Leguía de Bagua (UNIBAGUA) ha cumplido con las 15 características de la metodología de Latindex (Rios-Campos, Santamaría, Gutiérrez y Agreda, 2020).

En nuestras aulas convergen estudiantes de diversas etnias de las comunidades amazónicas: awajún, wampis. La familia lingüística de los Shuar, conformada por los awajún y wampis, se asienta en la región nororiental del Perú. Sus características culturales, simbolismo y rituales forman parte de su sistema holístico de ver la vida, la salud y la enfermedad, con formas propias de comunicación (MedinaIbañez, Mayca-Perez, Velásquez-Hurtado \& Llanos-Zavalaga, 2019).

Seguramente la frase más utilizada en estos meses es "la educación virtual en tiempo del COVID" o "la educación en tiempo de pandemia". Con la suspensión de las clases presenciales, la virtualidad pasó a formar parte de la vida delos actores del proceso de enseñanza -aprendizaje a la que se sumó la familia de ambos (Brítez, 2020).

La educación a distancia es una quimera, una alternativa para los que tienen equipos de una cierta calidad con acceso a internet en casa. Pero desgraciadamente hay demasiados estudiantes que no cuentan con ese recurso, ni con las condiciones materiales, ambientales y de espacio para poder beneficiarse de esta opción (Murillo \& Duk, 2020). 
Actualmente nuestras actividades académicas presenciales en el Perú han sido reemplazadas por enseñanza virtual o a distancia, debido a la pandemia del COVID-19 que azota a todo el mundo. De esta manera el ciclo académico 2020-I pese a las dificultades que han surgido como la conectividad permanente, la ausencia de algunos estudiantes debido al proceso de contagio que surge en la zona de las comunidades originarias, se suma el distanciamiento de los docentes debido a la modalidad de enseñanza, el no contacto físico. Pese a esta realidad, surge la iniciativa de establecer un contacto más inmediato con los estudiantes a través de vivencias de los propios participantes que reflejan su conocimiento ancestral, pero de una forma más lúdica, creativa e innovadora.

La historieta se convierte en una herramienta visual atractiva que plasma no solo una secuencia de sucesos de un determinado suceso, sino refleja su historia, se transfiere la cosmovisión particular de los pueblos originarios ante hechos o sucesos relacionados a la física y la matemática. Esta secuencia narrativa impacta en sus lectores, quienes se apropian de este nuevo conocimiento relacionándolo con el conocimiento sistematizado.

Este recurso didáctico contribuye a la mejora de los aprendizajes, permite desarrollar las habilidades de interpretación del mundo desde una perspectiva ingeniosa y cotidiana de lo que acaece a su alrededor, producto de su memoria, que al trasladarlas en secuencias de imágenes permite conservar sus costumbres, sus tradiciones, revalorar su cultura. Sin embargo, en este proceso de revaloración es necesaria la interacción con un agente lector, quien al entrar en contacto con esta historia, hechos o sucesos también le da un valor y se produce el intercambio cultural.(Macas, Mera, \& Ramírez, 2017)

Estas actividades creativas generan aprendizajes contextualizados en un ambiente participativo, dinámico y didáctico, ya que su estructura secuenciada, gráfica y ágil permite no solo leer la historia, sino apropiarse del mensaje del texto, aun en aquellos estudiantes que presentan problemas de comprensión lectora.(Agüero, García, Sanchéz, \& Guzmán, 2012)

La historieta persigue como finalidad narrar una historia, pero en forma entretenida empleando recursos verbales y no verbales, por lo tanto, puede incluir recursos de humor o ironía relacionados con la temática abordada. De esta manera, puede utilizarse no solo en la literatura sino como una estrategia aplicada a las ciencias para acercar a los estudiantes al mundo científico en forma lúdica estimulando sus habilidades creativas pero direccionadas a afianzar aprendizajes significativos y contextualizados. (Viau, Szigety, \& Tintori, 2015)

Este recurso didáctico no solo permite plasmar las vivencias, relatos de los estudiantes de manera gráfica, sino permite establecer diversas relaciones interpersonales entre sus pares y el docente, por lo tanto, se convierte en una herramienta de comunicación eficaz entre los actores del proceso de enseñanza aprendizaje dentro de un plan de estudio específico. (Linares, García, \& Martínez, 2016) 
Los estudiantes al escribir las historietas evidencian sus competencias artísticas de diseño de las viñetas, los personajes, escenarios, cartuchos, tipos de globos, metáforas visuales, recursos de movimiento y sonido que han ido adquiriendo en su vida académica. Asimismo, habilidades para seleccionar historias de sus costumbres ancestrales y relacionarlos con los contenidos disciplinares de la Física y Matemática convirtiéndose en relatores de su tradición o cultura, pero relacionándolo con los conocimientos disciplinares.

En la figura 1 se muestra el proceso intercultural de enseñanza aprendizaje que se realiza en las aulas, donde los estudiantes interactúan a través del diseño y escritura de las historietas como herramienta para socializar su aporte cultural ancestral en las disciplinas de Física y Matemática. Estas interrelaciones se realizan entre el docente y estudiante tanto originario como mestizo, así como entre los mismos estudiantes produciéndose el intercambio o interacción cultural enmarcado en un espacio de respeto, tolerancia y aceptación a las diferencias culturales, donde los estudiantes originarios fortalecen su identidad cultural.

Figura 1. Proceso intercultural de enseñanza-aprendizaje

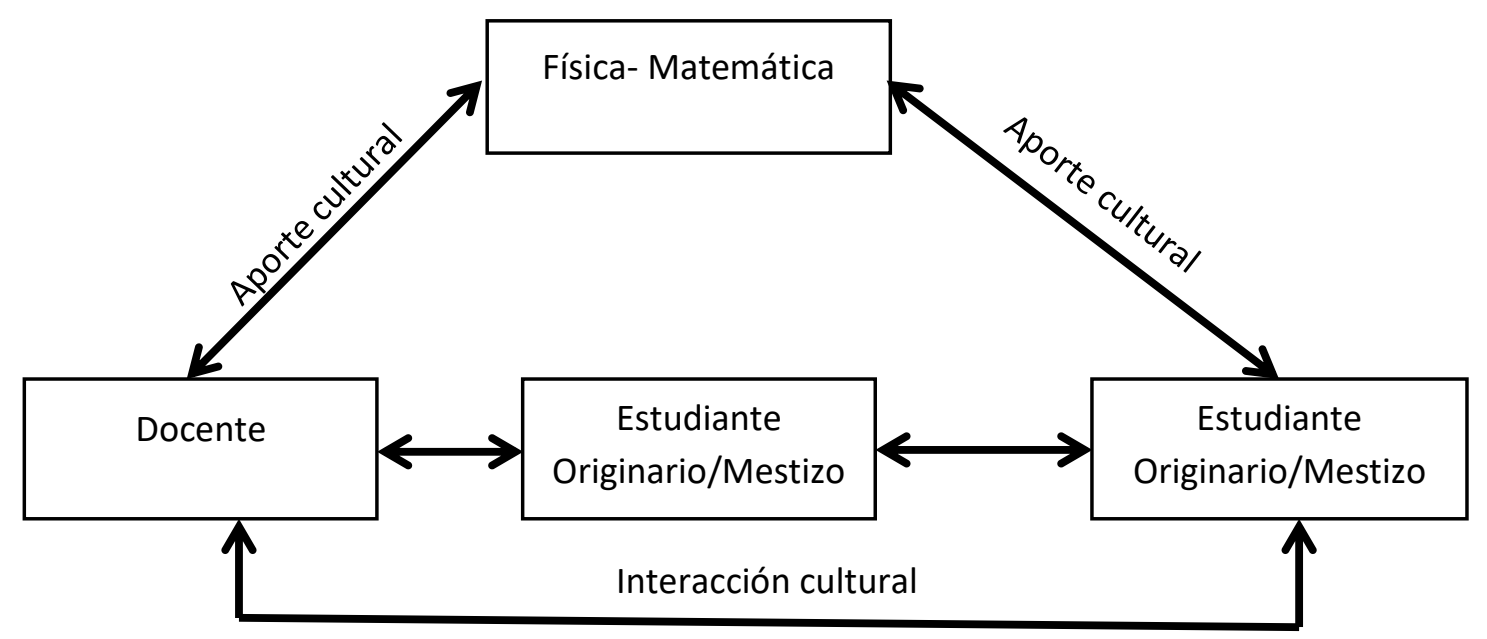

Fuente: Elaboración propia.

En la figura 2, se evidencia la función intercultural de la historieta en el proceso de enseñanzaaprendizaje, claramente se muestra dos espacios donde se enseña las disciplinas de la Física y Matemática. En el primer escenario, contenidos disciplinares donde se establece el predominio de una cultura, temas descontextualizados marcado por un lenguaje abstracto, formal de la ciencia; en el segundo escenario se muestra apertura para difundir conocimientos de la cultura de estudiantes mestizos- originarios, por lo tanto, es un conocimiento contextualizado a su realidad más inmediata, con la utilización de un lenguaje coloquial y de manera más gráfica y lúdica como es la historieta. 
Figura 2. La Historieta en su función intercultural en el proceso de enseñanza - aprendizaje

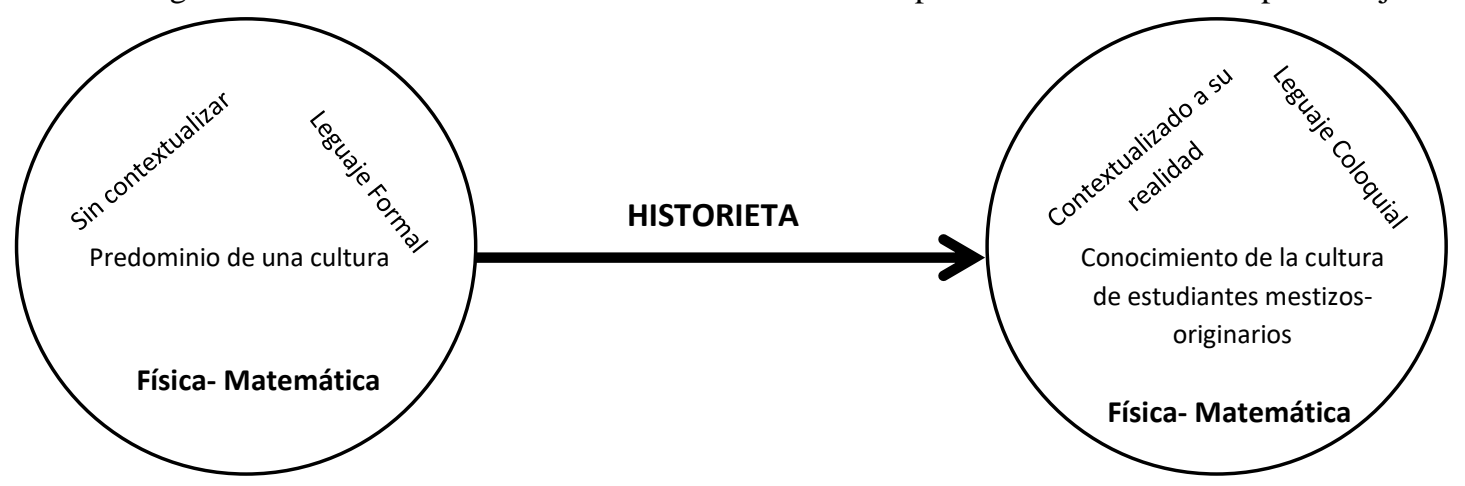

Fuente: Elaboración propia.

\section{METODOLOGÍA}

La presente investigación se realizó con un grupo de estudiantes del curso denominado Estática y Dinámica del ciclo III de la carrera profesional de ingeniería civil de la UNIFSLB. Este curso contiene en su estructura silábica temática referida a Equilibrio de los cuerpos y las condiciones que una estructura debe cumplir para mantenerlo. El aula del tercer ciclo lo componen 28 estudiantes, de los cuales 12 son jóvenes originarios de las comunidades amazónicas Awajún - Wampis, y los restantes estudiantes mestizos.

El trabajo se dividió en tres momentos y su aplicación se remonta desde el inicio del presente ciclo.

Primer momento. Se diagnosticó de manera verbal en sesiones virtuales con todos los estudiantes el nivel de conocimiento que se posee sobre elaboración de historietas y su frecuencia de visualización, así como referenciar cuales son las fuentes donde las encontró sea de manera impresa o digital. Aquí se aplicó una lista de cotejo, donde se evidencia que la mayoría de los estudiantes mestizos ya tenían conocimiento del tema, pues según argumentan habían desarrollado estas estructuras secuenciales en la EBR(Educación Básica Regular), además habían elaborado estas creaciones literarias, por lo tanto estaban en condiciones de realizar acciones creativas; sin embargo, los jóvenes originarios no recordaban este tema, por lo tanto presentan dificultad para diseñar y estructurar estos recursos gráficos. Ante estos resultados del diagnóstico se procedió a reforzar con material audiovisual de internet, así como de recursos asíncronos.

Segundo momento. Se procedió asignar como trabajo individual, cabe indicar que nuestro ciclo de estudios consta de 3 unidades, las cuales dentro de nuestro diseño de evaluación una de las actividades virtuales es el trabajo individual que consiste en programar una tarea con un determinado tiempo para que según los lineamientos o guía puedan hacer dicha asignación.

El trabajo individual consistía en la elaboración de una historieta en 1 página con 2 viñetas como mínimo, se les solicito que los personajes sean propios de su localidad y evidencie sus rasgos culturales, así como los saberes ancestrales, la temática sería cualquier tema tratado de Estática, finalmente, se 
temporizó este trabajo en 1 semana para poder elaborarlo y enviarlo por medio de nuestra aula virtual Google Classroom.

Tercer momento. Consistió en la socialización, este momento se consolidó generando 3 sesiones virtuales síncronas en donde cada uno de los estudiantes expuso su producción artística, así como la absolución de ciertas interrogantes que sus compañeros les hacían llegar de manera verbal o por medio del chat de la videoconferencia. Durante este proceso se procedió a la evaluación de cada historieta de acuerdo a la rúbrica de la Tabla 1. Cabe indicar que este momento fue muy importante porque se dejó en evidencia el intercambio cultural que se propiciaba así también como la tolerancia y el respeto durante la exposición de sus historietas y las características de sus personajes.

\section{RESULTADOS}

Las historietas producidas por estudiantes originarios de la carrera profesional de ingeniería civil en el curso de Estática se aprecian en la figura 3, donde se evidencia lo colorido y elocuente de sus expresiones, y al ser evaluadas con la rúbrica de la Tabla 1, donde un $72 \%$ de las producciones presentadas evidencian coherencia en la secuencialidad lógica de diálogos y gráficos, así como el $60 \%$ evidencia dominio adecuado del tema de Estática - Física y la fluidez para explicarlo o contextualizarlo a través de textos y diálogos pertinentes; un $70 \%$ evidencia un claro mensaje intercultural, los estudiantes que presentaron su producción hacen uso de personajes propios de su región y con trajes típicos así también aluden a saberes ancestrales Awajún. En conclusión, estas expresiones artísticas demuestran originalidad, creatividad y pertinencia generando impacto en sus lectores.

Figura 3. Producción de historietas de estudiantes originarios de ingeniería civil de la UNIFSLB

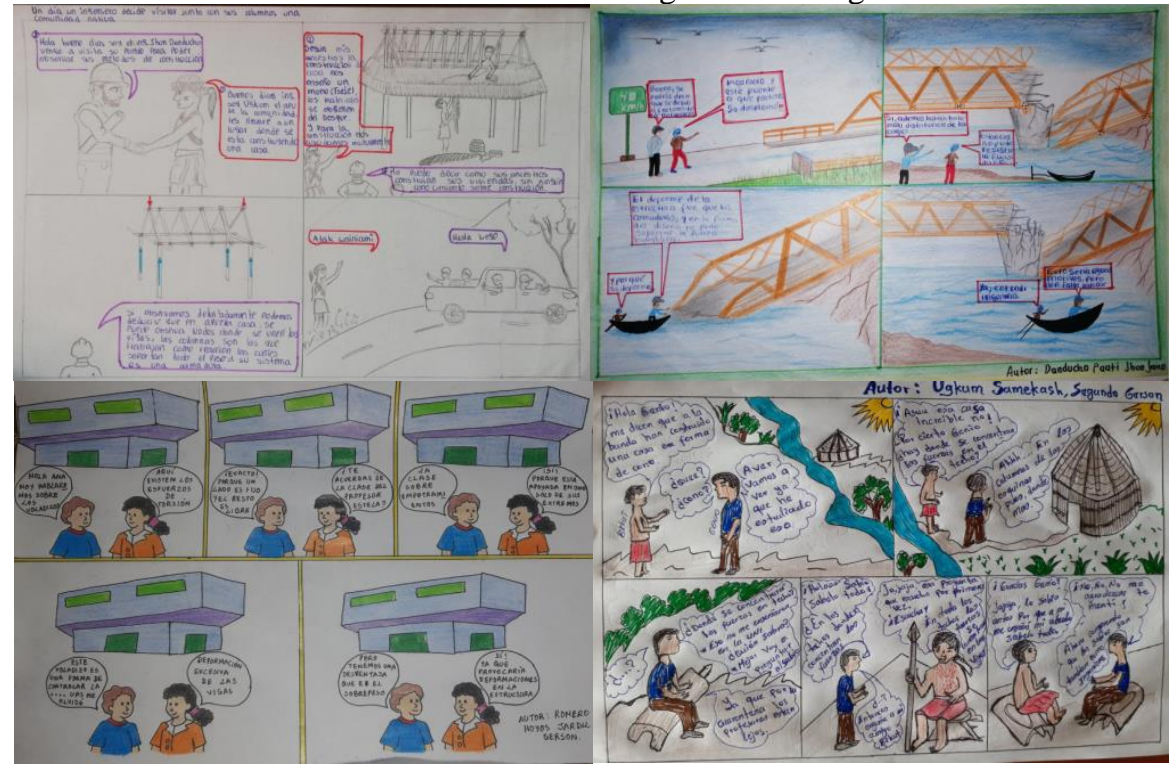

Fuente: Elaboración propia. 
En la figura 4 se puede apreciar las historietas producidas por estudiantes de origen mestizo donde se evidencia que un $80 \%$ de sus historietas muestran coherencia en cuanto a la presentación de sus episodios, secuencialidad lógica de diálogos y gráficos; un $74 \%$ evidencia un dominio del contenido, donde los textos y diálogos son pertinentes; un $28 \%$ evidencia un mensaje intercultural, ya que los lugares o prácticas, incluso los personajes son distantes a su realidad más inmediata, por el contrario son personajes extranjeros de series animadas. En conclusión, estas expresiones artísticas de estudiantes mestizos demuestran creatividad, utilización de estructuras modernas en sus imágenes, así como predominio del color y personajes de cómic para impactar en sus lectores.

Figura 4. Producción de historietas de estudiantes mestizos de ingeniería civil de la UNIFSLB.

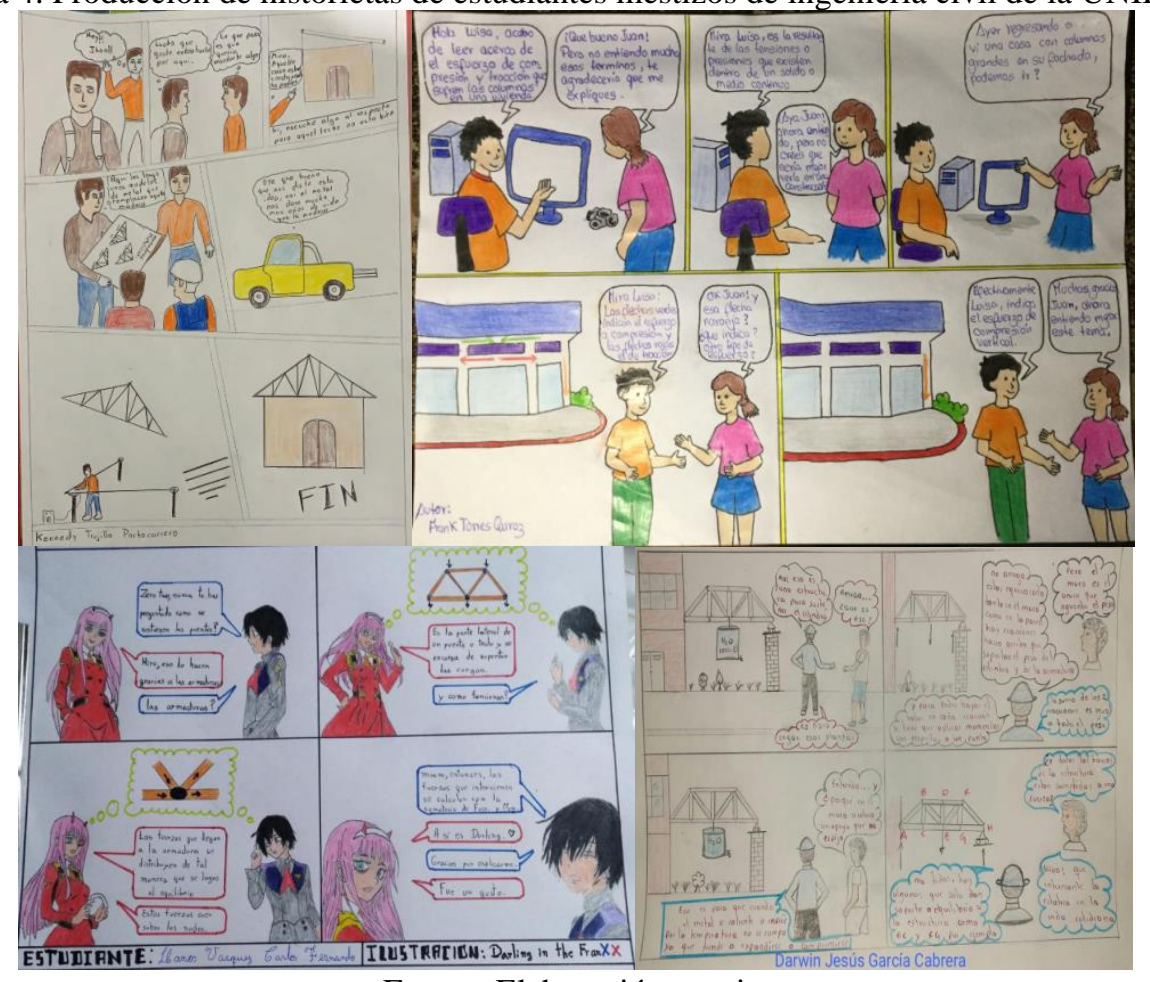

Fuente: Elaboración propia.

Las historietas producidas por los estudiantes tanto mestizos como originarios fueron evaluadas con la rúbrica de la tabla 1 donde se considera aspectos que ponderan la función intercultural de la historieta como recurso didáctico que refuerza el trabajo en las aulas de la UNIFSLB. Este instrumento fue de conocimiento anticipado de cada uno de los 28 estudiantes. 
Figura 5. Videoconferencia de socialización de historietas con los estudiantes de la UNIFSLB.

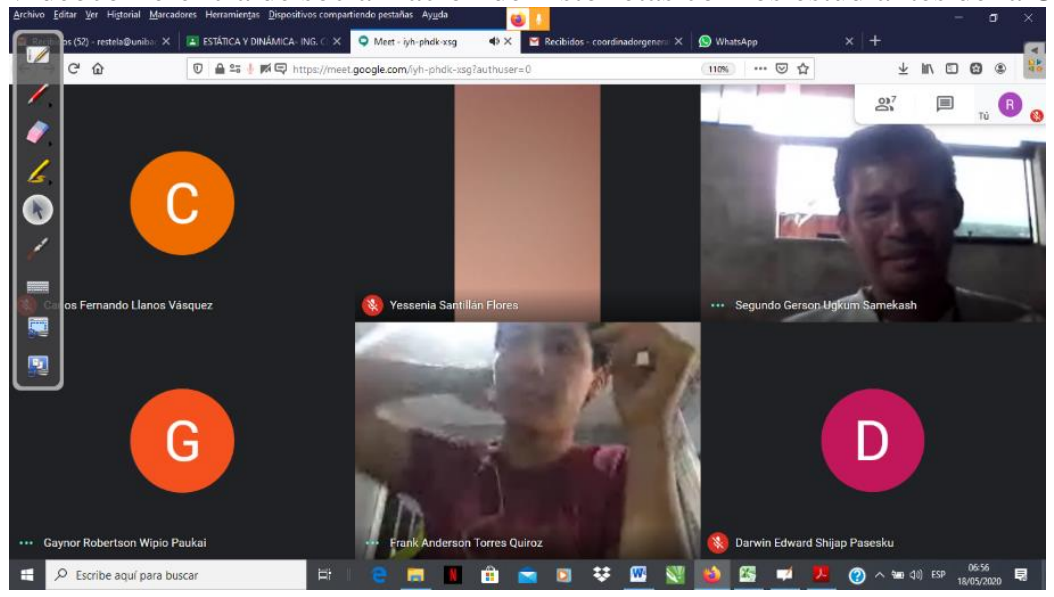

Fuente: Elaboración propia.

Tabla 1. Rúbrica para la evaluación de historietas presentadas por estudiantes de ingeniería civil de la UNIFSLB.

\begin{tabular}{|c|c|c|c|}
\hline CRITERIOS & SOBRESALIENTE & BUENO & POR MEJORAR \\
\hline Contenido & $\begin{array}{l}\text { Los textos y diálogos son } \\
\text { pertinentes para la viñeta y } \\
\text { denota un dominio del } \\
\text { contenido temático. }\end{array}$ & $\begin{array}{l}\text { Los textos y diálogos son en } \\
\text { su mayor parte adecuados } \\
\text { para la viñeta con cierto } \\
\text { manejo de contenidos } \\
\text { temáticos. }\end{array}$ & $\begin{array}{l}\text { Los textos y diálogos no } \\
\text { son adecuados para la } \\
\text { viñeta y denota poco } \\
\text { dominio de los } \\
\text { contenidos temáticos. }\end{array}$ \\
\hline Coherencia & $\begin{array}{l}\text { La historieta presenta una } \\
\text { secuencialidad lógica en } \\
\text { cuanto a los diálogos y } \\
\text { recursos gráficos dejando } \\
\text { entender con facilidad el } \\
\text { contenido. }\end{array}$ & $\begin{array}{l}\text { Se evidencia la carencia de } \\
\text { algún episodio resaltante. El } \\
\text { contenido de la historia, en } \\
\text { general, se entiende. }\end{array}$ & $\begin{array}{l}\text { Los episodios no se } \\
\text { evidencian } \\
\text { perfectamente en la } \\
\text { secuencia de viñetas de } \\
\text { la historieta, por lo } \\
\text { tanto no se entiende el } \\
\text { contenido de la historia. }\end{array}$ \\
\hline $\begin{array}{l}\text { Mensaje } \\
\text { intercultural }\end{array}$ & $\begin{array}{l}\text { Las imágenes, diálogos y } \\
\text { textos son pertinentes y } \\
\text { hacen alusión a sus saberes } \\
\text { ancestrales y revalora su } \\
\text { cultura con respeto y } \\
\text { tolerancia. }\end{array}$ & $\begin{array}{l}\text { Algunas imágenes, diálogos } \\
\text { y textos hacen alusión a sus } \\
\text { saberes ancestrales. }\end{array}$ & $\begin{array}{l}\text { Las imágenes, diálogos } \\
\text { y sus textos no hacen } \\
\text { alusión a sus saberes } \\
\text { ancestrales. }\end{array}$ \\
\hline Originalidad & $\begin{array}{l}\text { La historieta es original y } \\
\text { atractiva. Además, es } \\
\text { creativa e ingeniosa en su } \\
\text { conjunto No copia otra } \\
\text { historieta. }\end{array}$ & $\begin{array}{l}\text { El conjunto de la historieta es } \\
\text { adecuado. Su diseño es } \\
\text { cuidado. No copia otra } \\
\text { historieta. }\end{array}$ & $\begin{array}{l}\text { El conjunto de la } \\
\text { historieta no es } \\
\text { adecuado. Su diseño es } \\
\text { descuidado y/o copia } \\
\text { otra historieta. }\end{array}$ \\
\hline
\end{tabular}

Fuente: Elaboración propia.

La historieta como fin pedagógico posibilita integrar conocimientos científicos con los saberes del entorno dentro de espacios universitarios convirtiéndose en una oportunidad de aprendizaje contextualizado (Viau, Szigety, \& Tintori, 2015).

La producción de historietas desarrolla la creatividad y originalidad a través de la secuencialidad de los relatos, donde se desarrollan habilidades de análisis, organización e interpretación de contextos y situaciones, incluso es una forma de fomentar la lectura de una manera más gráfica y visual, logrando 
impactar en sus lectores, incluso en aquellos que presentan dificultad de comprensión lectora (Suárez, 2017).

La historieta permite acceder al conocimiento sistematizado y disciplinar de las ciencias a través de un lenguaje cotidiano y fluido dando un resultado alentador para lograr la comprensión del mundo a través de historias divertidas, con personajes de su entorno, escenarios y expresiones contextualizados. De esta manera, la historieta se convierte en un recurso didáctico que posibilita la integración del conocimiento disciplinar de la Física y Matemática con el saber ancestral, herramienta que coadyuva al fortalecimiento de la identidad cultural de los estudiantes originarios promoviendo la participación activa de todos los agentes del proceso enseñanza aprendizaje dentro del aula intercultural universitaria.

\section{CONCLUSIONES}

Las historietas resultan un recurso muy útil para la enseñanza - aprendizaje de la matemática y de la física universitaria dado que permite al estudiante entender estas asignaturas desde las construcciones civiles en su región y de esta forma poder socializarlas con un lenguaje simple y coloquial.

La función intercultural del uso de historietas resulta pertinente al evidenciarse en las producciones y socialización de sus creaciones de los estudiantes originarios y mestizos de ingeniería civil creando un ambiente de tolerancia e interés mutuo respecto a su cultura.

La existencia e interrelación de culturas mestizo-Awajún-wampis en las aulas universitarias de la UNIFSLB resultó reforzada con las expresiones de su cosmovisión a través de las historietas, donde se puede evidenciar que los jóvenes originarios de las comunidades Awajún y Wampis muestran en mayor proporción sus costumbres y saber ancestral en el abordaje de temas físicos. 


\section{REFERENCIAS BIBLIOGRÁFICAS}

Agüero, S., García, R., Sanchéz, D., \& Guzmán, J. (2012). Los cómics en la enseñanza de la Física: Diseño e implementación de una secuencia didáctica para circuitos eléctricos en bachillerato. (Spanish). Latin-American Journal of Physics Education, 666-481. http://search.ebscohost.com/login.aspx?direct=true \&db=ehh\&AN=90555594\&lang=es\&site=ehost-live

Brítez, M. (2020). La educación ante el avance del COVID-19 en Paraguay.Comparativo con países de la Triple Frontera. https://doi.org/10.1590/SciELOPreprints.22

González, T. (2019). La educación es un derecho, no es un privilegio. Diálogos sobre educación. Temas actuales en investigación educativa, 10(19), 00018. https://doi.org/10.32870/dse.v0i19.611

Leiva, J. (2017). Estilos de aprendizaje y educación intercultural en la escuela. Tendencias Pedagógicas, 29(2017), 197-214.

Linares, E., García, A., \& Martínez, L. (2016). Empleo de historietas para reforzar el aprendizaje del nivel superior en UPIBI - IPN / Employment of comic strips as Reinforcement Learning of Higher Education in UPIBI-IPN. RIDE Revista Iberoamericana Para La Investigación y El Desarrollo Educativo, 7(13), 1-14. https://doi.org/10.23913/ride.v7i13.230

Macas, L., Mera, D., \& Ramírez, J. (2017). Las historietas como estrategia metodológica para la enseñanza de $\begin{array}{llllll}\text { la Historia. } & \text { Maestro } & \text { 6ociedad. } & 15(1), & 646 .\end{array}$ https://maestroysociedad.uo.edu.cu/index.php/MyS/article/view/3310

Medina-Ibañez, A., Mayca-Perez, J., Velásquez-Hurtado, J. \& Llanos-Zavalaga, L. (2019). Conocimientos, percepciones y prácticas sobre el consumo de micronutrientes en niños Awajún y Wampis (Condorcanqui, Amazonas-Perú). Acta Médica Peruana, 36(3), 185-194. http://www.scielo.org.pe/scielo.php?script=sci_arttext\&pid=S1728-59172019000300002\&lng=es\&tlng=es.

Murillo, F., \& Duk, C. (2020). El Covid-19 y las Brechas Educativas. Revista latinoamericana de educación inclusiva, 14(1), 11-13. https://dx.doi.org/10.4067/S0718-73782020000100011

Paricio, M. (2005). Dimensión intercultural en la enseñanza de las lenguas y formación del profesorado. Revista Iberoamericana de Educación, 1-13.

Ríos, C. (2020). Interculturalidad y universidad. Journal of the Selva Andina Research Society, 11(1):57-00. http://www.scielo.org.bo/pdf/jsars/v11n1/v11n1_a07.pdf

Rios-Campos, C., Santamaría, N., Gutiérrez, K. y Agreda, H. (2020). Revistas científicas en universidades nacionales interculturales peruanas. Revista Venezolana de Gerencia (RVG), 25 (92) 1850-1862.

Saavedra, M. , Fuentes, D. , Lorenzo, D. , Álvaro, J., \& Martínez, H. (2014). La incorporación de las lenguas indígenas nacionales al desarrollo académico universitario: la experiencia de la Universidad Veracruzana. Revista de La Educación Superior, 43(171), 67-92.

Suárez, Y. (2017). La historieta digital como estrategia pedagógica para el aprendizaje de la matemática. UMA Editorial, 1-12.

Viau, J., Szigety, E., \& Tintori, M. (2015). La utilización del comics como recurso didáctico para favorecer la apropiación de contenidos físicos. Revista de Enseñanza de La Física, 27(1), 587-592. 